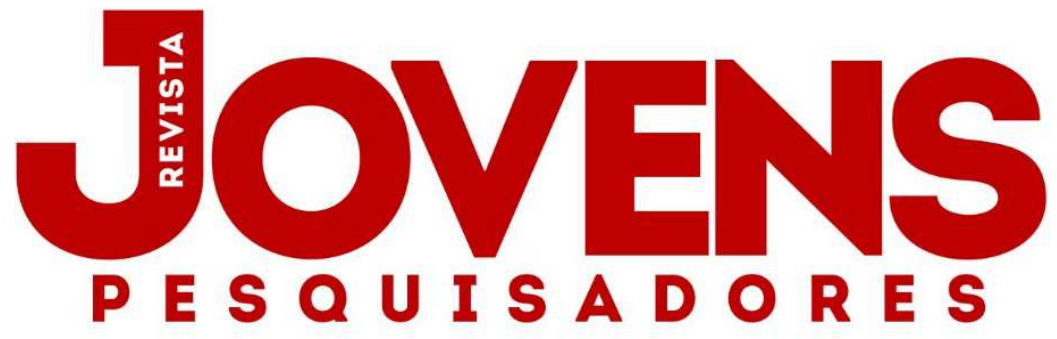

Doi: $10.17058 /$ rjp.v8i1.11834

Recebido em: 20/03/2018

Aceito em: 15/05/2018

\title{
A PRODUÇÃO DE SENTIDOS SOBRE A INCLUSÃO NA PESQUISA ACADÊMICA EM PSICOLOGIA E EDUCAÇÃO
}

\author{
GRANATA, B. C. ${ }^{1 ;}$ CAPPELLARI, A. ${ }^{2}$; COUTO, C. R. ${ }^{3}$; LOBLER, G. N. ${ }^{1}$; SANTOS, T. M. ${ }^{1}$; HILLESHEIM, B. ${ }^{4}$ \\ PALAVRAS CHAVE: Inclusão. Psicologia. Educação. Discurso.
}

\section{RESUMO}

0 presente trabalho aborda a inclusão como uma construção social que se disseminou de forma a se enraizar como valor "universal". Para analisar o discurso da inclusão, tomou-se como objeto as teses e dissertações do site Domínio Público. Através da busca pelo termo "inclusão" nas ferramentas de busca do site, após um "filtro de sentido", chegou-se ao total de 723 resultados, que foram organizados de acordo com a tabela de áreas do conhecimento do CNPq. Embora tenham sido encontrados resultados em todas as áreas principais, a maior concentração se deu em Educação (43,4\%) e Psicologia (8,9\%). Voltando o foco para estas, a análise baseou-se no título, resumo e nas palavraschave dos trabalhos, a fim de pensar os eixos adjetivação (adjetivos que aparecem vinculados à inclusão) e público (a quem se dirige a inclusão). Em "público", apesar da aparente concentração em torno da deficiência/necessidades educativas especiais ( $70 \%$ dos resultados), a grande variedade de sujeitos agrupados nessa categoria demonstra também um alargamento dos "limites" da inclusão. Por fim, a semelhança dos resultados das áreas de Educação e Psicologia indica um direcionamento da pesquisa sobre inclusão, de modo que o entendimento de diferentes áreas parece coincidir em linhas gerais.

\section{THE PRODUCTION OF SENSES ABOUT INCLUSION IN ACADEMIC RESEARCH IN PSYCHOLOGY AND EDUCATION}

\author{
KEYWORDS: Inclusion. Psychology. Education. Discourse.
}

\begin{abstract}
This article explores inclusion as a social construct that has disseminated to the point of being established as an "universal" value. In order to analyze the discourse of inclusion, the theses and dissertations uploaded in the website Domínio Público were taken as an object of study. By means of searching the term "inclusion" in the website's search tools, after a "filter of meaning", 723 results were found and later organized according to CNPq's table of fields of knowledge. Results were found in all the main fields, however, they appeared most often in the areas of Education $(43,4 \%$ of the total results) and Psychology (8,9\%). Focusing on these areas, the analysis used the titles, abstracts and keywords of the results in order to work with two axes: adjectivation (adjectives which appear connected to inclusion) and subjects (the public to whom inclusion is intended). In "subjects", despite the apparent predominance of disability/special educational needs $(70 \%$ of the results), the great variety of subjects grouped in this category also shows an enlargement of the "extent" of inclusion. Finally, the similarity between the results in the areas of Education and Psychology indicates a trend in the research about inclusion, such that the standpoints of different fields seem to coincide in general outlines.
\end{abstract}

\footnotetext{
${ }^{1}$ Acadêmicos do curso de Psicologia na Universidade de Santa Cruz do Sul.

2 Graduada em Psicologia pela Universidade de Santa Cruz do Sul.

${ }^{3}$ Graduada em Psicologia e Mestranda em Educação na Universidade de Santa Cruz do Sul.

4 Docente do Departamento de Psicologia na Universidade de Santa Cruz do Sul.
} 


\section{INTRODUÇÃO}

Um determinado discurso sempre encontrará sustentação em certas condições de existência que propiciem a sua emergência e sua difusão. Em outras palavras, os discursos somente se fazem possíveis quando inseridos em certa ordem discursiva, sempre histórica e cultural, que regula e delimita o dizer verdadeiro (FOUCAULT, 1998). Tal compreensão de discurso norteia a pesquisa Inclusão, diferença e políticas públicas: uma cartografia, na qual se insere o presente trabalho. Pautando-se nesse conceito, a pesquisa compreende a inclusão como uma construção social recente, que ganha projeção de forma mais intensa principalmente no final do século XX e início do século XXI, período em que se verifica uma acentuada disseminação de slogans como "Saúde para todos", "Educação para todos", "Luz para todos", etc. (HILLESHEIM, 2013). Tais dizeres penetram a sociedade através dos mais variados espaços, assumindo, gradativamente, um estatuto de verdade, de modo que se encontram, hoje,

(...) já naturalizados, indissociados da ideia de dever/necessidade, e muitas vezes tomados como parâmetro de legitimidade ou validação moral de determinadas medidas ou ações (...). Tal naturalização da ideia de inclusão pressupõe o entendimento generalizado de que essa seja um valor instituído a priori, tomado como princípio de "ação correta", constituindo-se enquanto base moral inquestionável (GRANATA et al, 2017).

Desse modo, a pesquisa que fundamenta este artigo investiga as formas como se constituem e circulam os discursos sobre a inclusão em diversos âmbitos sociais. Alinhado com esse intuito, o presente texto toma como objeto de análise as teses e dissertações contidas nos registros do site Domínio Público, uma biblioteca virtual de acesso livre gerenciada pelo governo federal. A partir de uma análise geral da intensidade da produção e distribuição dos trabalhos que abordam a inclusão entre as diversas áreas de conhecimento, faz-se possível a discussão a respeito da articulação entre os discursos da inclusão e a produção acadêmica. A partir disso, realiza-se uma análise mais aprofundada das áreas de Educação e Psicologia, que tiveram um volume de resultados significativamente maior do que o encontrado nas demais áreas de conhecimento (respectivamente 43,4\% e 8,9\% do total, distribuindo-se o restante entre 47 áreas distintas). Essa análise mais precisa, realizada sobre o conteúdo dos trabalhos das duas áreas, produziu dados que proporcionam reflexões mais detalhadas sobre as formas mais frequentes com que a lógica de inclusão se faz presente no campo da pesquisa acadêmica, e é para essas reflexões que se volta este trabalho.

\section{CONTEXTUALIZAÇÃO DA TEMÁTICA: A INCLUSÃO COMO IMPERATIVO CONTEMPORÂNEO}

A importância de se pensar e entender os discursos como algo cujos efeitos ultrapassam o campo do dizer reside no entendimento de Michel Foucault de que discursos "não são, como se 
poderia esperar, um puro e simples entrecruzamento de coisas e palavras" (2004, p. 54), não se restringindo a um conjunto de signos que serviriam somente para designar objetos, mas se constituem como práticas que produzem os próprios objetos de que falam.

Dito isso, esta pesquisa parte da noção de Foucault (1998) de que um determinado discurso somente se fará possível a partir de determinadas condições de emergência que propiciem a sua existência, ou seja, estará sempre inserido em uma ordem discursiva. Essa ordem, sempre vinculada ao período histórico, molda-se de acordo com as transformações sociais, e varia em maior ou menor grau de acordo com cada tempo e cada sociedade. É ela que determina o que é ou não correto, moral e desejável, estabelecendo dessa forma o que pode ou não ser dito. A partir disso, é possível pensar a inclusão como um imperativo do nosso tempo (LOPES, 2009), ou seja, como um enunciado que emerge no contemporâneo, adquirindo determinada forma e que repercute nos mais diversos espaços, da mídia ao meio acadêmico.

No caso do Brasil, como situado por Veiga-Neto e Lopes (2011), essa explosão discursiva sobre inclusão ocorrerá principalmente a partir dos dois mandatos do presidente Fernando Henrique Cardoso (1995 a 2002), comparando-se, nesse sentido, ao que Foucault (1985) apontava a respeito dos discursos sobre a sexualidade a partir do século XVIII. Desse modo, a noção de inclusão penetra a sociedade de múltiplas formas, enraizando-se nela de modo a ser, hoje, reconhecida como verdade intrínseca, isenta de qualquer suspeita. "Para dizer em poucas palavras, a inclusão é vista como um imperativo que a todos se impõe, graças ao caráter natural que, não problematicamente, é atribuído a ela" (VEIGA-NETO; LOPES, 2011, p. 126). Assim, fica esquecido o caráter histórico e cultural envolvido nesse processo. Nesse sentido,

\begin{abstract}
A naturalização dos processos sociais funciona como uma espessa camada de concreto que sepulta, sob si, o caráter inventado de tais processos. Esquecendo-se de que foram inventados, de que dependeram de determinadas contingências históricas localizadas e datadas, esses processos sociais passam a ser considerados como necessários, imutáveis e, assim, imunes à crítica. Esse é o caso da inclusão escolar (Ibidem, p. 126-127).
\end{abstract}

Além disso, acompanhando a proliferação de tais discursos, percebe-se um "alargamento" nos próprios limites da inclusão, que passa a abranger uma diversidade cada vez maior de grupos e pessoas (VEIGA-NETO, 2001). Nesse sentido, Veiga-Neto e Lopes (2011) colocam que a noção de inclusão se amplia para uma diversidade de sujeitos muito maior, passando a se referir a todos aqueles que de alguma forma sofrem discriminação negativa. A ideia de discriminação negativa é compreendida aqui a partir das contribuições de Castel (2008), o qual sugere uma diferenciação entre discriminação positiva e negativa, sendo que a primeira diria respeito a ajudar aqueles que têm menos, objetivando sua integração ao regime comum, enquanto a segunda, por sua vez, tenderia não apenas a ajudar os menos favorecidos, mas também os marcar com características que não se podem apagar, criando um estigma sobre os sujeitos, o qual também pode servir para sua exclusão. 
Como citado anteriormente, tais movimentos ocorreram com maior força a partir das políticas do segundo mandato de FHC, sendo mantidos e ampliados nos governos Lula e Dilma.

Por fim, é importante ressaltar que, ao trabalhar a lógica da inclusão como uma construção e um imperativo atual, não se trata de formular um julgamento no sentido de marcar tais discursos como verdadeiros ou falsos, certos ou errados, bons ou maus. Para além de tais juízos de valor, pretende-se, mediante sua problematização, buscar compreender como os jogos de forças os constituem e os sustentam, ou seja, na direção apontada por Foucault (2004), "definir esses objetos sem referência ao fundo das coisas, mas relacionando-os ao conjunto de regras que permitem formálos como objetos de um discurso e que constituem, assim, suas condições de aparecimento histórico" (p. 53).

Portanto, o discurso da inclusão é tomado, no presente trabalho, a partir de seu caráter inventado e temporal. Tendo isto em vista, discute-se, a seguir, a pesquisa propriamente dita, buscando evidenciar como tal discurso se dissemina nas pesquisas acadêmicas, mais especificamente, nas áreas da Educação e da Psicologia.

\section{PROCEDIMENTOS INVESTIGATIVOS}

0 primeiro passo para a produção dos dados referentes aos materiais contidos nos registros do site Domínio Público foi a busca pelo termo "inclusão" nos campos "título" e "palavras-chave" (assincronicamente) das ferramentas de busca do site, na categoria de "teses e dissertações". Depois, registraram-se os títulos dos trabalhos encontrados, separados por área, em documento de texto, repetindo-se este procedimento para cada uma das áreas de conhecimento. Vale observar que só houve registros de trabalhos que tratavam sobre a inclusão entre os anos de 2004 a 2011, período que concentra o maior número de teses e dissertações no site de modo geral, sendo o volume de materiais datados de fora deste período significativamente mais baixo.

Uma vez que a palavra inclusão possui usos diversos, realizou-se, sobre o registro geral dos títulos dos trabalhos que traziam o termo "inclusão" no título ou palavras-chave, um "filtro de sentido", descartando os materiais que traziam a palavra "inclusão" em um sentido diverso daquele que se coloca como objeto de estudo da pesquisa. Como exemplo dos materiais descartados, podese citar: "A inclusão do ensino de bioética na graduação médica: uma possibilidade de inovação curricular", "A superação do paradigma racionalista e a possibilidade de inclusão do comando mandamental na sentença condenatória", "Avaliação dos níveis de inclusão da torta de macaúba [acrocomiaaculeata (jacq.) lodd. exmart.] na alimentação de caprinos". Além disso, foram necessários alguns cuidados no registro dos títulos em decorrência de casos de repetições de um mesmo trabalho no site por motivos diversos - como erros de digitação no nome do autor ou no título de um dos envios, divergências nos anos de registro de cada versão e mesmo trabalhos 
enviados em mais de uma área de conhecimento. Dessa forma, após a identificação da repetição, os trabalhos excedentes foram excluídos do registro geral da pesquisa, com exceção dos casos em que as repetições ocorreram por envio do trabalho em mais de uma área, uma vez que a exclusão de alguma versão implicaria necessariamente na escolha por contabilizar o trabalho em determinada área e não em outra. Nessas condições, chegou-se a um total de 723 teses e dissertações, distribuídas entre 49 áreas distintas.

Após, os dados foram organizados de acordo com as áreas de conhecimento do CNPq. A partir disso, desenvolveram-se tabelas, expondo os resultados de modo a provocar as primeiras reflexões. A seguir, a fim de complementar os dados quantitativos, escolheu-se, com base na representatividade numérica, as áreas de Educação e Psicologia - que, somadas, equivalem a 52,3\% do total de resultados encontrados - para uma primeira análise qualitativa. Para tanto, foram organizados dois eixos, chamados de adjetivação e público. Por adjetivação se compreenderam os casos em que o termo inclusão aparecia acompanhado de algum adjetivo (inclusão escolar, inclusão social, inclusão digital, etc.), ou mesmo os casos em que a própria inclusão era empregada como adjetivo, como, por exemplo, em "educação inclusiva" ou "projeto inclusivo". Já no eixo público,

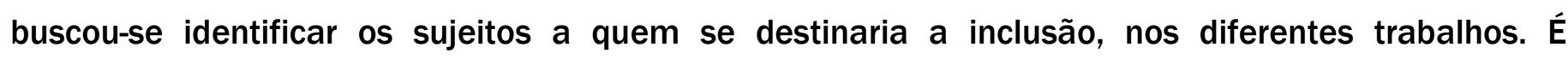
indispensável mencionar que a organização e exposição desses resultados, principalmente quando em forma de registros numéricos, exige uma série de cuidados e observações, por serem fruto de diversos critérios que se baseiam em necessárias decisões e enfoques da própria pesquisa. Todos esses serão explicados junto à exposição dos dados produzidos, no tópico seguinte.

\section{RESULTADOS}

\subsection{A DISSEMINAÇÃO DO DISCURSO DA INCLUSÃO NAS DIFERENTES ÁREAS DO} CONHECIMENTO

Para iniciar a exposição dos dados produzidos durante a execução da pesquisa, traz-se o Quadro 1, apresentando uma primeira organização dos resultados obtidos, de acordo com a tabela de áreas do conhecimento do CNPq. Trata-se de uma tabela geral, que visa trazer uma noção inicial da distribuição dos resultados do site entre as oito áreas principais (que englobam todas as outras, dividindo-se em subáreas). Ainda, pontua-se o conjunto dos trabalhos cujas áreas identificadas no site não constam na tabela de áreas do conhecimento do CNPq, composto principalmente por aquelas nomeadas no site como "Interdisciplinar" e "Multidisciplinar". 
Quadro 1: Quantidade de resultados contendo o termo “inclusão" no título/palavras-chave em cada uma das principais áreas do conhecimento

\begin{tabular}{|l|c|}
\hline \multicolumn{1}{|c|}{ ÁREA DO CONHECIMENTO } & NÚMERO DE RESULTADOS \\
\hline 1. CIÊNCIAS EXATAS E DA TERRA & 7 resultados \\
\hline 2. CIÊNCIAS BIOLÓGICAS & 18 resultados \\
\hline 3. ENGENHARIAS & 31 resultados \\
\hline 4. CIÊNCIAS DA SAÚDE & 4 resultados \\
\hline 5. CIÊNCIAS AGRÁRIAS & 139 resultados \\
\hline 6. CIÊNCIAS SOCIAIS APLICADAS & 448 resultados \\
\hline 7. CIÊNCIAS HUMANAS & 32 resultados \\
\hline 8. LINGUÍSTICA, LETRAS E ARTES & \\
\hline ÁREAS DO SITE DOMÍNIO PÚBLICO & 42 resultados \\
QUE NÃO CONSTAM NA TABELA DE & \\
ÁREAS DO CONHECIMENTO DO CNPq & \\
\hline
\end{tabular}

Fica evidente a discrepância entre as quantidades de trabalhos encontrados nas áreas de Ciências Humanas e Ciências Sociais Aplicadas, cujos resultados somam $81,2 \%$ do total de resultados encontrados na pesquisa. Porém, é importante mencionar que, embora apresente um número bastante inferior de trabalhos, proporcionalmente, a área de Linguística, Letras e Artes também possui uma concentração significativa de resultados, visto ser essa a menor de todas as áreas principais, composta apenas pelas três subáreas citadas em seu nome. 0 fato de que a subárea de Linguística aparece entre as dez com maior número de resultados encontrados, como demonstra a seguir o Quadro 2, ratifica essa concentração.

Quadro 2: Dez subáreas com maior número de resultados contendo o termo "inclusão" no título/palavras-chave no site Domínio Público

\begin{tabular}{|c|c|}
\hline SUBÁREA & NÚMERO DE RESULTADOS \\
\hline EDUCAÇÃO & 314 \\
\hline PSICOLOGIA & 64 \\
\hline DIREITO & 34 \\
\hline SOCIOLOGIA & 31 \\
\hline INTERDISCIPLINAR & 26 \\
\hline SERVIÇO SOCIAL & 22 \\
\hline COMUNICAÇÃO & 19 \\
\hline CIÊNCIA DA INFORMAÇÃO & 17 \\
\hline LINGUÍSTICA & 16 \\
\hline ADMINISTRAÇÃO & 15 \\
\hline
\end{tabular}

Para a construção desse quadro, considerou-se os resultados encontrados em cada área somados aos das respectivas subáreas, quando houve. Dessas dez inclusas na tabela, cinco fazem parte da área principal de Ciências Sociais Aplicadas, três de Ciências Humanas (incluindo Educação e Psicologia), uma de Linguística, Letras e Artes e a última, "Interdisciplinar", integra o conjunto das áreas que não constam na tabela do CNPq. Embora seja considerável o contraste entre o número de resultados da área mais numerosa, a Educação, e a décima, a Administração, a pulverização dos demais resultados chama ainda mais a atenção quando se considera que os resultados dessas dez 
subáreas, somados, equivalem a $77,18 \%$ do total encontrado na pesquisa, distribuindo-se os $22,82 \%$ restantes entre 39 subáreas diferentes.

Apesar de deixarem clara a concentração de resultados em áreas específicas, com destaque para a Educação - que teve um papel importante no início das discussões sobre inclusão, ocupando ainda um lugar de bastante relevância nesse debate -, esses dois primeiros quadros também demonstram o quanto as discussões sobre a inclusão penetram inúmeras áreas, mesmo que em intensidades variadas. Chama a atenção no Quadro 10 fato de que todas as oito principais áreas de conhecimento do CNPq apresentaram teses ou dissertações que falam de alguma forma sobre a inclusão nos registros do site Domínio Público, desde as Ciências Agrárias ou Engenharias até as Ciências Humanas. Igualmente significativo é o fato de que 49 subáreas diferentes apresentam algum trabalho sobre o tema, mesmo que a maioria dos resultados se concentre em apenas algumas. Por mais distantes que possam parecer, todas as áreas encontram algo a pensar e dizer sobre a inclusão. Esses dados indicam que, embora tenham se originado e despertado interesse inicialmente em áreas específicas, os discursos sobre a inclusão, hoje, ultrapassam esses limites, colocando-se como objeto de estudo de diversas áreas, não mais ficando restritos a determinados campos.

\subsection{UM OLHAR SOBRE OS SENTIDOS DA INCLUSÃO NAS ÁREAS DA EDUCAÇÃO E} PSICOLOGIA

A seguir, passa-se para os quadros formulados a partir da análise específica das áreas de Educação e Psicologia, começando pela primeira, que apresentou um total de 314 trabalhos que abordam a inclusão. Os quadros 3 e 4 referem-se à análise do eixo adjetivação, e apresentam os números de incidência das expressões mais frequentes entre as teses e dissertações da área de Educação, sendo o Quadro 3 referente à inclusão adjetivada e o Quadro 4 à inclusão adjetivando, ou seja, utilizada como adjetivo. Os números da coluna denominada "número de ocorrências" equivalem ao número de trabalhos em que se contabilizou cada expressão, valendo a mesma regra para os quadros seguintes.

Quadro 3: "Inclusão adjetivada" na Educação

\begin{tabular}{|c|c|}
\hline INCLUSÃO ADJETIVADA & NÚMERO DE OCORRÊNCIAS \\
\hline Inclusão escolar & 119 \\
\hline Inclusão educacional & 19 \\
\hline Inclusão social & 64 \\
\hline Inclusão digital & 31 \\
\hline Inclusão/exclusão (ou “inclusão \\
excludente”) & 15 \\
\hline
\end{tabular}


Além das expressões expostas no quadro, há outros casos em que a palavra inclusão foi utilizada nos trabalhos acompanhada de algum adjetivo, como "inclusão pré-escolar", "inclusão sociocultural”, “inclusão familiar”, "inclusão voluntária”, "inclusão radical”, entre outros. Entretanto, essas expressões foram utilizadas pouquíssimas vezes, não configurando, por isso, um marcador para a análise deste trabalho.

Quadro 4: "Inclusão adjetivando" na Educação

\begin{tabular}{|c|c|}
\hline INCLUSÃO ADJETIVANDO & NÚMERO DE OCORRÊNCIAS \\
\hline Educação inclusiva & 63 \\
\hline Escola inclusiva & 24 \\
\hline Espaço/ambiente & 6 \\
(educacional/escolar) inclusivo & 8 \\
\hline Prática(s) inclusiva(s) & 7 \\
\hline Processo inclusivo & \\
\hline
\end{tabular}

Novamente, foram reunidos na tabela os exemplos com frequência mais significativa, tendo havido várias outras ocorrências da inclusão utilizada como adjetivo com recorrência muito menor, sendo a maioria encontrada em um único trabalho. Dentre elas: "educação profissional inclusiva", "ações inclusivas", "classes inclusivas", "caráter inclusivo", "cultura inclusiva”, "dinâmica inclusiva”, "discursos inclusivos", etc.

Traz-se a seguir os quadros referentes ao eixo adjetivação na área de Psicologia, que apresentou um total de 64 teses ou dissertações que abordam a inclusão. Do mesmo modo, o Quadro 5 apresenta os números de ocorrências das expressões mais frequentes para a inclusão “adjetivada”, e o Quadro 6 se refere à inclusão “adjetivando".

Quadro 5: "Inclusão adjetivada" na Psicologia

\begin{tabular}{|c|c|}
\hline INCLUSÃo ADJETIVADA & NÚMERO DE OCORRÊNCIAS \\
\hline Inclusão social & 23 \\
\hline Inclusão escolar & 20 \\
\hline Inclusão educacional & 4 \\
\hline Inclusão/exclusão & 11 \\
\hline Inclusão profissional & 3 \\
\hline Inclusão perversa & 2 \\
\hline Inclusão digital & 1 \\
\hline Inclusão efetiva & 1 \\
\hline
\end{tabular}

Quadro 6: "Inclusão adjetivando" na Psicologia

\begin{tabular}{|c|c|}
\hline INCLUSÃO ADJETIVANDO & NÚMERO DE OCORRÉNCIAS \\
\hline Educação/escola/ensino inclusiva(o) & 17 \\
\hline "processo(s) de inclusão (...)/inclusivo" & 17 \\
\hline Proposta(s) inclusiva/de inclusão & 5 \\
\hline
\end{tabular}

Tal como nos dados anteriores, além das expressões inseridas na tabela, houve também outros casos em que a inclusão foi utilizada como adjetivo nos trabalhos da área de Psicologia, 
porém com uma frequência muito menor, sendo a maioria isolados em um único trabalho. Alguns exemplos são "práticas inclusivas", "projeto inclusivo", "políticas públicas inclusivas", "salas de aula inclusivas", "princípios inclusivos", etc.

A partir da análise do eixo "adjetivação", destaca-se o quanto a relação com a educação é recorrente nos termos utilizados pelos autores, sendo "inclusão escolar", "inclusão educacional", "escola inclusiva", "educação inclusiva" e "ensino inclusivo" expressões bastante frequentes, mesmo na área de Psicologia. Pode-se relacionar tal questão à própria emergência do discurso da inclusão, que surge fortemente entrelaçado com a questão da inclusão escolar para pessoas com deficiência, na qual, como assinalam Lasta e Hillesheim (2011, p. 92), "a escola, como instituição obrigatória, é colocada no lugar de promotora de condições de igualdade para todos".

Além disso, assinala-se que, nas áreas de Educação e Psicologia, além da recorrência das expressões ligadas à educação, é significativa a quantidade de vezes em que a inclusão aparece vinculada ao termo exclusão. Fica claro o entendimento, por grande parte dos autores, da inclusão como oposto de exclusão, em uma perspectiva dicotômica. Nesse sentido, Veiga-Neto e Lopes fazem o alerta para "(...) os usos alargados da palavra exclusão, quando ela é entendida como "outro da inclusão" (2011, p. 122).

Seguindo para o eixo público, o Quadro 7 demonstra os grupos identificados com maior frequência como sujeitos de inclusão na área de Educação, e o Quadro 8 traz os dados da área de Psicologia.

Quadro 7: Públicos da inclusão na Educação

\begin{tabular}{|c|c|}
\hline PÚBLICO & NÚMERO DE APARIÇÕES \\
\hline Pessoas com deficiência/NEE & 216 \\
\hline $\begin{array}{c}\text { População de baixa renda ou em } \\
\text { situação de vulnerabilidade social }\end{array}$ & 24 \\
\hline $\begin{array}{c}\text { Sujeitos pensados a partir de sua } \\
\text { relação com a educação }\end{array}$ & 21 \\
\hline $\begin{array}{c}\text { Alunos/jovens/crianças com } \\
\text { dificuldades de adaptação }\end{array}$ & 11 \\
\hline Adolescentes em conflito com a lei & 4 \\
\hline População rural & 4 \\
\hline Idosos & 4 \\
\hline Inclusão ligada ao preconceito racial & 4 \\
\hline Mulheres & 3 \\
\hline Homossexuais & 2 \\
\hline $\begin{array}{c}\text { Inclusão em sentido amplo/público } \\
\text { não identificado no resumo }\end{array}$ & 31 \\
\hline
\end{tabular}

Igualmente, além dos grupos apresentados na tabela, houve trabalhos na área de Educação que discutiam a inclusão direcionada, por exemplo, a pacientes com HIV/AIDS, famílias de pessoas 
com deficiência e indivíduos estrábicos. Esses e alguns outros casos de públicos citados nos trabalhos apareceram apenas em trabalhos isolados e, por isso, não compõem a tabela acima.

Quadro 8: Públicos da inclusão na Psicologia

\begin{tabular}{|c|c|}
\hline PÚBLICO & NÚMERO DE APARIÇÕES \\
\hline Pessoas com deficiência/NEE & 47 \\
\hline $\begin{array}{c}\text { População de baixa renda ou em } \\
\text { situação de vulnerabilidade social }\end{array}$ & 6 \\
\hline Adolescentes em conflito com a lei & 2 \\
\hline Jovens trabalhadores & 2 \\
\hline Idosos & 2 \\
\hline
\end{tabular}

Outros trabalhos identificados na área de Psicologia também traziam como públicos da inclusão "pais que possuem filhos com deficiência", "grupos minoritários" de forma geral e "educador e aluno" (sem maiores explicações), sendo estes exemplos presentes em casos isolados.

É necessário destacar que a decisão de expor os resultados do eixo público em forma de tabelas pode ser arriscada e, certamente, bastante controversa, devendo esses dados, por isso, serem vistos com muito cuidado. Diferentemente do eixo adjetivação, em que foi feita uma busca por termos, a análise do público teve de passar, na maioria das vezes, pela leitura e interpretação dos resumos dos trabalhos para se identificar quem os autores compreendiam como "objeto da inclusão". Essa organização em "blocos" de sujeitos, necessária para a exposição dos dados gerais das áreas de forma factível, provou-se uma tarefa bastante complicada e, também, arriscada, por exigir o agrupamento de sujeitos ou grupos muitas vezes bastante específicos e diversos entre si, com base em elementos gerais em comum. Portanto, simplesmente olhar para as expressões utilizadas para nomear cada grupo e para o número de ocorrências respectivo pode ser enganoso, de modo que a maior categoria identificada, a de "pessoas com deficiência/NEE (Necessidades Educativas Especiais)", por exemplo, engloba pessoas com Síndrome de Down, autismo, lesão medular, surdez, cegueira, déficit de atenção e hiperatividade, entre várias outras. É justamente por compreender o quanto é reducionista reunir uma diversidade tão grande de sujeitos e apresentá-la como um número em um bloco pretensamente homogêneo que se considera válidos os quadros $7 \mathrm{e}$ 8 com fins de comparação quantitativa, ou seja, para trazer uma noção do quanto de interesse se direciona para certas "condições gerais" na pesquisa acadêmica sobre inclusão. De fato, a análise do eixo "público" serviu antes para mostrar o quão diversos são os sujeitos compreendidos como passíveis de inclusão, e o quanto se expandem as fronteiras entre o "excluído" e o "incluído".

Por fim, os quadros 9 e 10 trazem uma comparação entre as percentagens dos resultados em relação ao total das áreas de Educação e Psicologia, considerando os termos e grupos que tiveram os maiores números de resultados em ambos os eixos. Dessa maneira, o Quadro 9 se refere ao eixo adjetivação, e o Quadro 10 ao eixo público. 
Quadro 9: Comparação entre Educação e Psicologia referente ao eixo "adjetivação"

\begin{tabular}{|c|c|c|}
\hline ÁREA & $\begin{array}{c}\text { EDUCAÇÃO (total } \\
314)\end{array}$ & $\begin{array}{c}\text { PSICOLOGIA (total } \\
64)\end{array}$ \\
\hline INCLUSÃO SOCIAL & $64(20,4 \%)$ & $23(35,9 \%)$ \\
\hline INCLUSÃO ESCOLAR & $119(37,9 \%)$ & $20(31,2 \%)$ \\
\hline INCLUSÃO DIGITAL & $31(9,9 \%)$ & $1(1,6 \%)$ \\
\hline INCLUSÃO/EXCLUSÃO & $14(4,5 \%)$ & $11(17,2 \%)$ \\
\hline
\end{tabular}

Quadro 10: Comparação entre Educação e Psicologia referente ao eixo "público"

\begin{tabular}{|c|c|c|}
\hline ÁREA & $\begin{array}{c}\text { EDUCAÇÃO (total } \\
314)\end{array}$ & $\begin{array}{c}\text { PSICOLOGIA (total } \\
64)\end{array}$ \\
\hline PESSOAS COM DEFICIÊNCIA/NEE & $216(68,8 \%)$ & $47(73,4 \%)$ \\
\hline POPULAÇÃO DE BAIXA RENDA & $24(7,6 \%)$ & $6(9,3 \%)$ \\
OU EM SITUAÇÃO DE & & \\
VULNERABILIDADE SOCIAL & & \\
\hline
\end{tabular}

Assim, feitas as ressalvas acima sobre a diversidade de sujeitos que são englobados por essas categorias gerais, aponta-se o quanto a ideia de inclusão, embora generalizada e pautada em diferentes contextos e voltada para sujeitos diversos, está fortemente relacionada tanto ao campo das deficiências, quanto à pobreza. Em ambas as situações, entende-se que a inclusão se inscreve em uma estratégia de regulação, controle e governo da população, a partir do que Lasta e Hillesheim (2011) discutem como política preventiva de controle do risco daqueles representados como passíveis de ações de normalização. Embora as autoras discutam essa questão a partir da inclusão escolar e os ditos anormais, entende-se, no presente trabalho, que, no contexto de um país marcado pela desigualdade socioeconômica, como é o caso do Brasil, as ações inclusivas voltadas para as populações de baixa renda ou grupos vulneráveis (os quais, nas políticas públicas, estão estreitamente ligados às questões da pobreza) também se inserem nessa lógica.

\section{CONSIDERAÇÕES FINAIS}

A análise dos dados produzidos permite, tomando como amostra as teses e dissertações contidas nos registros do site Domínio Público (plataforma de abrangência nacional), fazer algumas observações a respeito dos modos como se colocam e circulam os discursos sobre a inclusão na produção acadêmica. A partir da discussão realizada anteriormente, pode-se observar não apenas o quanto o debate sobre a inclusão ainda se concentra em áreas específicas, mas também o quanto já encontra sustentação, em maior ou menor grau, em todas as áreas do conhecimento. Nessa perspectiva, as diferentes áreas, por maiores que sejam as diferenças de método de estudo e foco de interesse, voltam-se em alguma medida para o debate sobre a inclusão. Na medida em que se entende, a partir de Foucault (1998), que o discurso obedece a determinadas regras, as quais confirmam ou interditam a produção e circulação dos ditos, pode-se afirmar que a produção desse volume de trabalhos acadêmicos sobre inclusão não é fortuita ou natural, mas se inscreve naquilo 
que é fomentado e permitido dizer em nossa época. Nesse cenário, à semelhança do que discute Sommer (2007) a respeito dos conceitos que são permitidos ou impedidos de circular nas escolas, entende-se que tais ditos sobre inclusão ordenam a realidade, constituindo uma sociedade que se pretende inclusiva.

É possível, a partir dos resultados da análise sobre as áreas de Educação e Psicologia, vislumbrar um direcionamento geral da pesquisa acadêmica sobre a inclusão, uma vez que essas representam, juntas, mais da metade do total de resultados encontrados na pesquisa. É curiosa a semelhança entre os resultados das duas áreas quando se comparam as percentagens de resultados em relação ao total (quadros 9 e 10), não apenas em relação à frequência com que determinados sujeitos e condições aparecem como objeto de inclusão (em ambas as áreas, o grupo abrangente de "pessoas com deficiência/NEE" foi objeto de aproximadamente $70 \%$ dos trabalhos, assim como o grupo definido como "população de baixa renda ou em situação de vulnerabilidade social" ficou em torno de $7 \%$ a $9 \%$ ), mas também em relação aos adjetivos que aparecem ligados à inclusão. A maior divergência é a ocorrência da expressão "inclusão digital", que embora se faça presente em quase $10 \%$ dos trabalhos da Educação, aparece em apenas um trabalho da área de Psicologia, indicando ser esse tema uma tendência mais significativa no meio educacional.

Porém, o que mais chama a atenção é a frequência com que se faz referência à educação no debate sobre a inclusão, sendo que a expressão "inclusão escolar", presente em $37,9 \%$ dos trabalhos da área de Educação, mantém-se alta na Psicologia, fazendo-se presente em $31,2 \%$ das teses e dissertações. Veiga-Neto e Lopes discutem essa relação entre a noção de inclusão e a educação, remetendo esse vínculo ao início do debate sobre a temática de forma mais intensa no país:

\footnotetext{
Durante os dois mandatos de Fernando Henrique Cardoso (FHC), entre 1995 e 2002, vimos surgir com intensidade no vocabulário político e educacional a palavra inclusão. De início, essa palavra designava uma alternativa capaz de resolver vários problemas educacionais, principalmente os que envolviam a participação de pessoas com deficiência na escola. $E$, na medida em que a escola vem sendo vista, desde há muito, como uma instituição capaz de contribuir decisivamente para resolver quase todos os problemas sociais, a inclusão escolar seria decisiva para a ampliação da participação de todos em uma sociedade melhor, mais justa, etc. (2011, p.121, grifo dos autores).
}

Por fim, ao buscar compreender quem é o público da inclusão, a dificuldade na formulação dos quadros 7 e 8 demonstra o quanto a disseminação desses discursos acompanha uma proliferação de excluídos, no sentido de que há um alargamento nos limites da inclusão, passando cada vez mais pessoas a serem consideradas como passíveis de serem incluídas, de modo que se torna muito difícil ou mesmo impossível definir os sujeitos que fazem parte da massa de excluídos: todos podem, de certa forma, ocupar esse lugar, em algum momento. A esse respeito, Veiga-Neto e Lopes (2011) trazem que, a partir do governo FHC, a noção de inclusão, que de início abarcava especialmente pessoas com deficiências, amplia-se e passa a abranger todos aqueles que sofrem discriminação negativa - os autores apontam o uso alargado do termo, passando-se a utilizar 
“inclusão” "(...) para se referir a um número cada vez maior e mais diverso de indivíduos a incluir ou já incluídos" (p. 122). As definições escorregam de tal forma que as próprias noções do que é deficiência, desvantagem (e vantagem?), falta ou insuficiência se modificam, ao ponto em que não se sabe em qual grupo contabilizar um trabalho quando o autor coloca "indivíduos estrábicos" como sujeitos de inclusão, ou quando o autor discute que a inclusão se volta com frequência para as pessoas com deficiência, mas que é necessário que se incluam também as "famílias de pessoas com deficiência".

Desse modo, os discursos produzem novas categorias, novos modos de ver e pensar o mundo, sendo que cada vez mais indivíduos são passíveis de in(ex)clusão. Nessa direção, Lopes (2007) coloca que, em nosso tempo, a inclusão ocupa um espaço equivalente ao espaço criado para a exclusão. Cria-se exclusão e, então, clama-se por inclusão.

Nesse sentido, os dados indicam como o discurso da inclusão tem se multiplicado nas diferentes esferas da vida dos sujeitos, tornando-se, no âmbito das pesquisas acadêmicas, uma questão importante para a produção do conhecimento, presente em um significativo número de investigações que resultaram em teses e dissertações. Além disso, pode-se pensar que as duas áreas nas quais se encontram o maior número de produções - a Educação e a Psicologia - têm se preocupado, ao longo dos últimos anos, com a descrição e a prescrição de práticas legitimadas pela noção de inclusão. Assim, percebe-se como a inclusão, enquanto uma invenção de nosso tempo, vem transformando modos de se relacionar com os saberes e com diferentes grupos populacionais, constituindo a todos como sujeitos da inclusão.

\section{REFERÊNCIAS}

CASTEL, Robert. A discriminação negativa: cidadãos ou autóctones? Petrópolis: Vozes, 2008. FOUCAULT, Michel. A arqueologia do saber. Rio de Janeiro: Forense Universitária, 2004.

FOUCAULT, Michel. A ordem do discurso. 4.ed. São Paulo: Edições Loyola, 1998.

FOUCAULT, Michel. História da sexualidade. A vontade de saber. $7^{a}$ ed. Rio de Janeiro: Edições Graal, 1985.

GRANATA, Bruno Corralo et al. A proliferação do discurso da inclusão: produção de sentidos nas diferentes áreas de conhecimento. In.: $7^{\circ}$ Seminário Brasileiro de Estudos Culturais e Educação e $4^{\circ}$ Seminário Internacional de Estudos Culturais e Educação: Políticas do ressentimento, do medo e da raiva: reverberações na educação. Canoas, 2017. Disponível em: http://www.sbece.com.br/resources/anais/7/1495515333_ARQUIVO_texto_completo_v.final.pdf.

Acesso em: 25 fev. 2018.

HILLESHEIM, Betina. É preciso incluir! Políticas públicas e o imperativo da inclusão. In: CRUZ, L.R. da; RODRIGUES, L.; GUARESCHI, N.M.F. (org.). Interlocuções entre a psicologia e a política nacional de assistência social. Santa Cruz do Sul: EDUNISC, 2013. Disponível em: https://craspsicologia.files.wordpress.com/2013/03/interlecuc3a7c3b5es-entre-a-psicologia-e-apnas.pdf. Acesso em: 15 mar. 2018.

LASTA, Letícia; HILLESHEIM, Betina. Políticas públicas de inclusão escolar: a produção e o gerenciamento do anormal. In: THOMA, A.S.; HILLESHEIM, B. (org.). Políticas de inclusão. Gerenciando riscos e governando as diferenças. Santa Cruz do Sul: EDUNISC, 2011. p. 87-108. 
LOPES, Maura C. Inclusão escolar: currículo, diferença e identidade. In: LOPES, M. C.; Dal'Igna, M. C. In/exclusão nas tramas da escola. Canoas: Editora Ulbra, 2007. p. 11-33.

LOPES, Maura Corcini. Políticas de inclusão e governamentalidade. Educação e Realidade, v. 34, n. 2, p. 153-169, mai/ago 2009.2 Disponível http://seer.ufrgs.br/educacaoerealidade/article/view/8297/5536 Acesso em: 02 mar.2018.

SOMMER, Luís Henrique. A ordem do discurso escolar. Revista Brasileira de Educação. V. 12, n. 14, p. 57-67, jan/abr. 2007.

VEIGA-NETO, Alfredo. Incluir para excluir. In: LARROSA, J.; SKLIAR, C. Habitantes de babel: políticas e poéticas da diferença. Belo Horizonte: Autêntica, 2001. p. 105-118.

VEIGA-NETO, Alfredo; LOPES, Maura Corcini. Inclusão, exclusão, in/exclusão. Verve, v. 30, p. 121-135, 2011. Disponivel em: http://revistas.pucsp.br/index.php/verve/article/download/14886/11118 Acesso em: 02 mar. 2018. 